\title{
Statistical Teaching Cognitive Survey for Students of business school*
}

\author{
Li Yinguo \\ School of Business, Jiangsu Normal University, Xuzhou, 221116, China \\ liyinguocumt@sina.com
}

Keywords: Statistical cognitive; Curriculum reform; Methodology discipline; Teaching methods

\begin{abstract}
Based on the investigation of learning situation of statistical in business school, a three-way data component analysis method was used to analyze the student's learning effect. Then, reveal students' views of teaching objectives, method and examination mode. Finally, summarizes the main tasks of the implementation of the curriculum reform of statistics in China.
\end{abstract}

\section{Introduction}

Statistics is a multidisciplinary cross discipline which is closely related to social, computer, information science and etc. Statistics was built on real measurement problems; utility is still its greatest asset [1]. In the information age, the importance of statistical work and education increasingly highlights. In China, statistics has been a core class for business and management students granted by ministry of education.

Reform of statistics education has been seen emergence and has advocated to engaging students in the active exploration for the past few decades. Moore summarized these trends with regard to issues for introductory statistics courses [2]. Cobb and Moore argued strongly that the introductory course should begin with exploratory data analysis and descriptive statistics [3]. Scheaffer suggested that it is important to correct educational strategies that encourage deep learning approaches [4]. Only a few of research articles compared the learning approaches between Asian and Australian students in statistics [5]. At present, there are three NCTM Standards documents were used as the basis for Principles and Standards for School Mathematics and provide further focus school mathematics curricula with the release of Curriculum Focal Points [6]. The statistics education community has recently provided a more detailed vision for the substance of Pre-K-12 statistics with the release of the Guidelines for Assessment and Instruction in Statistics Education (GAISE) report [7].

In China, many well-known universities provide that Statistics must be opened up in the sophomore year for business administration major, focusing on the basic principle of statistics, then, in their third grade, courses of "statistical software and applications" are set up, teaching them the mainstream of statistical software operation methods and training their abilities of social statistics work. Feng \&Di proposed that applied universities should develop the applied abilities of students, combine teaching practice with teaching experience and reform the teaching method and strengthen the extracurricular practice [8]. In recent years, with the deepening of curriculum reform, more and more teachers think that it is necessary to reform the current statistical education mode in the light of the characteristics of students and the goal of cultivating applied talents. Apparently, the assessment research of teaching effect and teaching cognitive of statistics curriculum will has great role in promoting the construction of university disciplines of statistics and statistical personnel training.

\footnotetext{
* This work is partially supported by Jiangsu university philosophy and social sciences fund project (2014 sjb406) (China) and Doctorate teachers' scientific research support project of Jiangsu Normal University, (12 xwr016 ) ( China).
} 


\section{Data Source}

Some research has shown that a lot of variables can affect students' approaches and their learning passion, such as Reference [9-10]. These variables include teaching methods, learning theories, assessment ways, teaching objectives and learning experiences.

In this paper, the survey data was collected from the statistical questionnaire about statistics teaching cognitive of the sophomore and the junior students of school of business, Jiangsu Normal University, Jiangsu, China. The survey involved in eight professions, such as Finance, Insurance, Economics, International Trade, Business Management, Marketing, Accounting, Logistics Management. We handed out a total of 428 questionnaires and take back 402 of them, the number of valid questionnaires is 366 . Questionnaire is aimed at five aspects of the investigation, such as teaching methods, teaching material, learning enthusiasm, evaluation methods, teaching goal and so on, which are shown in table 1. In the survey, in view of the statistical test scores of students, we made statistics respectively and divided them into four categories. A: more than 90 points, B: $80-90$ points, C: $60-80$ points, D: 60 points below. Details are shown in Table 1.

Table 1 Distribution of 366 Students of Jiangsu Normal University

\begin{tabular}{|l|c|c|c|c|}
\hline \multicolumn{1}{|c|}{ points } & $90-100$ & $80-90$ & $60-80$ & $0-60$ \\
\hline Frofessions & 11 & 18 & 25 & 3 \\
\hline Insurance & 8 & 13 & 18 & 4 \\
\hline Economics & 5 & 9 & 19 & 4 \\
\hline International Economy and Trade & 7 & 14 & 18 & 5 \\
\hline Business Management & 7 & 21 & 16 & 3 \\
\hline Marketing, & 6 & 17 & 15 & 4 \\
\hline Accounting & 10 & 23 & 14 & 2 \\
\hline Logistics Management & 6 & 15 & 20 & 6 \\
\hline
\end{tabular}

\section{Statistical Cognitive Analysis of Students}

According to the statistical test scores, students can be divided into four groups, namely A, B, C and D. The main student test scores are given priority to with 60 to 90 points, students who scored 90 points above or below 60 points are relatively few in number.

From the survey data, for student in group A, first, as to teaching methods, $30 \%$ students of group A pay more attention to the Laboratory teaching method; $20 \%$ of them pay more attention to the Practice teaching; other $20 \%$ of them like case teaching more. Second, in the aspect of teaching material, $33.33 \%$ students of group A think that statistic is too abstract and other $26.67 \%$ students Point out that statistical theory involve too many formulas. Third, in the aspect of learning enthusiasm, $68.33 \%$ students generally show interested in statistic; Fourth, as to the inspection way, $36.67 \%$ students like survey report and $28.33 \%$ of them like combined test of Written and computer; Fifth, in the aspect of teaching goal, $55 \%$ students give priority to the teaching mode which combines theory with practice.

For student in group B, just like students of group A, most of them also pay more attention to the Laboratory teaching and case teaching methods; In the aspect of teaching material, most of them also think statistics theory too abstract and formula too more; In the aspect of learning enthusiasm, 52.31\% of them are interested in statistics mostly; On the inspection way, $33.85 \%$ of them like survey report to be seen as test scores; As to the teaching target, they are also easier to accept the teaching of theory combined with practical. Obviously, students from A and B groups show a basic consistent on the cognition of statistics.

For student in group $\mathrm{C}$, as to teaching methods, $27.52 \%$ students pay more attention to the Laboratory teaching and 22.82 of them pay more attention to Case teaching; in the aspect of teaching 
material, 32.21\% students think that statistic involves too many formulas; In learning enthusiasm, $53.02 \%$ students show generally interesting; As to the inspection way, $41.61 \%$ students like survey report as the test and $30.87 \%$ of them also like combined test of Written and computer; At last, in the aspect of teaching goal, most of them give priority to the teaching mode which combines theory with practice too.

For student in group D, most student $(35.48 \%)$ more like discussion teaching methods and $29.03 \%$ of them more like Laboratory teaching method; In the aspect of teaching material, the vast majority of students thought that statistical formula is too more (74.19\%); As much as $80.65 \%$ of students said they have no interest in statistics; As to the assessment way, $77.42 \%$ of them like survey report and no one of them like the theory exam; Thought on the teaching target, they given priority to teaching mode of weak theory and heavy practice.

From the view of abnormal points in Figure 1, class A and class B students' abnormal points are interesting and theory and practice, they are all over the three quarters quantiles, which shows students with good exam scores of class A and class B have a strong interesting in statistics and prefer the combination of theory and practice teaching mode; In C class, the abnormal points is students' general interesting, and it is also over three quarters quantiles. $\mathrm{C}$ class students, whose test scores between 60-80 points, are obviously not much interested in statistics, so its performance is in the middle level; Class D students' abnormal points have three, respectively is: uninteresting, Survey report and more formula. but They also are all over three-quarters quantiles, this shows that for the poor test scores of class D students statistic has too more al formula and is no interesting. They prefer to survey practice examination way. Obviously, from above analysis, students' enthusiasm for statistical course of learning determines the final grades in statistical learning.

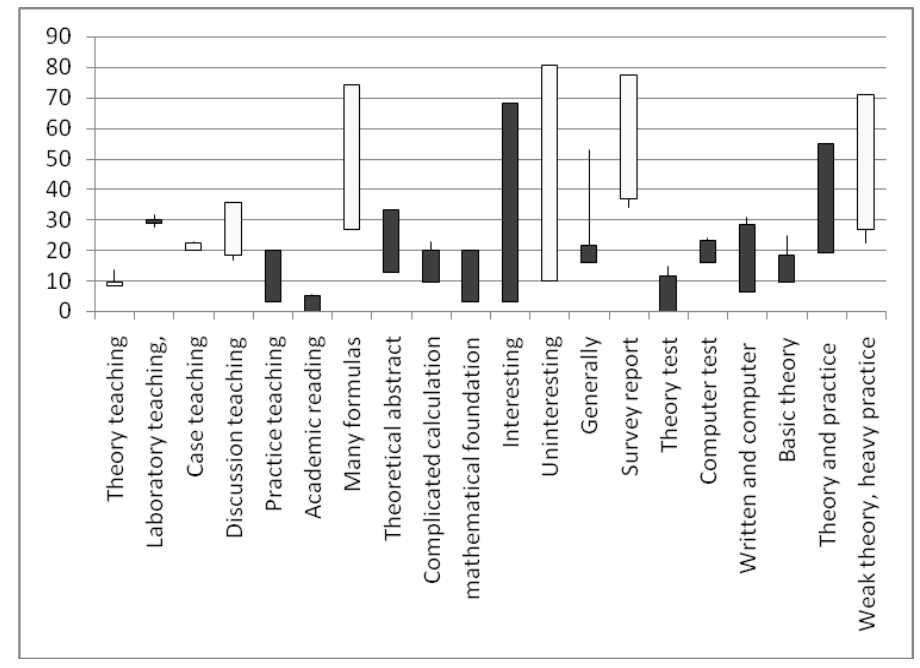

Fig. 2 Box diagram of 20 statistical cognitive variables

In China, most of students majoring in economics or management are come from arts students in high school, although they also has mathematics in the university entrance exam, but rather a part of the students in mathematics learning and there is no advantage. They are more hope can get rid of clearance of mathematics learning through the professional education of higher education. In school of business, Basis Accounting and Statistics Theory are the two courses that students fail the most. What cause this situation is that the eyeful is formulas and numbers and there are many complicated calculations process in the principle of statistical teaching material. In contact with such a course, students will first impressions are most lasting. Moreover, in our syllabus and reality program, almost no subsequent course can again enable the content of the statistics, so it is difficult to cause student's study interest and attention. 


\section{Conclusions}

In order to develop to meet the need of social and economic development of the statistics personnel, according to the characteristics of statistical disciplines, we should set up the scientific statistics teaching idea and reasonable statistical program, choose excellent statistical teaching materials and cultivate strong ability of application of statistics. Statistics has a vast subject system and rich subject matter and discipline characteristic is very significant. Statistics is both a strong theoretical and strong applicability.

As methodology discipline, statistics has strong applicability, thus we should guide the students to apply the basic statistical theory and the method to the real world. We should make them master the most basic statistics professional skills. In fact, application is the life of statistics. For different schools and colleges, we should have different features, contact with different practical applications, such as business terms should be focus on the application of economic, financial and management.

We face an open international environment, the demand for information and capacity is increasing every day. As the method of data processing and analysis, statistic is also more and more widely used in natural science and social science research, production, management and daily life. Therefore, the selection of statistical teaching material and the teaching content should not only consider the international conventions, but also should be suitable for national conditions of China. Excellent teaching material can make teachers teach relaxed, at the same time to make the students less detours.

Statistics is a discipline with very strong applied and statistics professional stressed the importance of the application very much. Statistical thinking and skills training cannot be separated from practice, must be able to withstand the practice examination, and also needs continuous development in practice. The interpretation of the statistical data more combined with the actual situation, so you must pay attention to cultivate students' ability to solve problems and to participate in the management ability. On the one hand, teachers in the teaching process should deal with imparting knowledge and cultivating ability and pay attention to cultivate the students' independence and autonomy. It is also the first class professional statistics at the university. Case teaching is a practice of direct mode Proposed, based on training students' analysis ability and the ability to deal with practical problems.

We should draw lessons from foreign teaching modes, such as emphasis on practice, attach importance to use the computer, strengthen the application of computer and so on. We should link the statistical methods, such as statistical inference and hypothesis test, regression, statistical modeling, etc., with the real world, such as economic, business, medical, industrial quality control. Some computer software, such as SPSS, SAS, S-plus, should be used by teachers to train the students to apply statistical theory knowledge to solve practical problems and the output results of the interpretation.

\section{References}

[1]L. S. Richard, Statistics education: Perusing the past, embracing the present, and charting the future, Statistical Education, 7(2001) 89-97.

[2]G. Cobb, and D. Moore, Mathematics, Statistics, and Teaching, American, 1997.

[3]D. Moore, New Pedagogy and New Content: The Case of Statistics, International Statistical Review, 65(1997)123-127.

[4]R.L. Scheaffer, Statistics education: Perusing the past, embracing the present, and charting the future, Newsletter of the Section on Statistical Education of the American Statistical Association, 7(2007)13-27.

[5]Groth R. E, Analysis of an online case discussion about teaching stochastics, Mathematics Teacher Education and Development, 7(2006) 53-71 
[6]F. Fennell, Focal points-where we are, and what's next? NCTM News Bulletin, 43(2007)3-11.

[7]C. A., Franklin, G., Kader, D., Mewborn, J., Moreno, R., Peck, M., Perry, \& R. Scheaffer, Guidelines for assessment and instruction in statistics education (GAISE) report: A pre-K-12 curriculum framework. [Online: http://www.amstat.org/education/gaise/]

[8]B.Y, Feng, G.H. Di, A probe into the reform of teaching mathematical statistics in applied universities, Theory and Practice of Education,34(2014)50-51.

[9]T.A. Angelo, A teacher's dozen: Fourteen general research-based principles for improving higher learning in our classrooms, American Association for Higher Education Bulletin, 45(1993)3-13.

[10]Steinhorst R.K., Keeler C.M, Developing Material for Introductory Statistics Courses from a Conceptual, Active Learning Viewpoint. Journal of Statistics Education, 3(1995)31-42. 